Meta

Journal des traducteurs

Translators' Journal

\title{
The Translation Process: Methods and Problems of its Investigation
}

\section{Wolfgang Lörscher}

Volume 50, numéro 2, avril 2005

Processus et cheminements en traduction et interprétation Processes and Pathways in Translation and Interpretation

URI : https://id.erudit.org/iderudit/011003ar

DOI : https://doi.org/10.7202/011003ar

Aller au sommaire du numéro

Éditeur(s)

Les Presses de l'Université de Montréal

ISSN

0026-0452 (imprimé)

1492-1421 (numérique)

Découvrir la revue

Citer cet article

Lörscher, W. (2005). The Translation Process: Methods and Problems of its Investigation. Meta, 50(2), 597-608. https://doi.org/10.7202/011003ar
Résumé de l'article

Après une brève introduction sur l'analyse de processus mentaux (section 1), ainsi qu'une esquisse d'une recherche approfondie décrite dans cet article (section 2), nous présentons notre méthodologie (section 3). Elle consiste en une sélection de données ainsi qu'une analyse et évaluation de ces dernières. La section 4 décrit une analyse stratégique du processus de traduction faite sur trois niveaux : le niveau des éléments de stratégies de traductions (4.1.); des stratégies elles-mêmes (4.2); ainsi que des versions (5). La fin de l'article compare brièvement les processus de traduction entre professionnels et non-professionnels.
Ce document est protégé par la loi sur le droit d'auteur. L'utilisation des services d'Érudit (y compris la reproduction) est assujettie à sa politique d'utilisation que vous pouvez consulter en ligne.

https://apropos.erudit.org/fr/usagers/politique-dutilisation/ 


\title{
The Translation Process: Methods and Problems of its Investigation
}

\author{
WOLFGANG LÖRSCHER \\ University of Leipzig, Leipzig, Germany \\ WolfgangLoerscher@web.de
}

\begin{abstract}
RÉSUMÉ
Après une brève introduction sur l'analyse de processus mentaux (section 1), ainsi qu'une esquisse d'une recherche approfondie décrite dans cet article (section 2), nous présentons notre méthodologie (section 3). Elle consiste en une sélection de données ainsi qu'une analyse et évaluation de ces dernières. La section 4 décrit une analyse stratégique du processus de traduction faite sur trois niveaux: le niveau des éléments de stratégies de traductions (4.1.); des stratégies elles-mêmes (4.2); ainsi que des versions (5). La fin de l'article compare brièvement les processus de traduction entre professionnels et non-professionnels.
\end{abstract}

\begin{abstract}
After the introductory remarks about the analysis of mental translation processes (section 1) and an outline of the investigation reported on in this paper (section 2) the methodology used is presented (section 3). It consists of the methods for data elicitation as well as for data analysis and evaluation. Section 4 describes a strategic analysis of translation processes carried out on three levels: the level of the elements of translation strategies (4.1), of the strategies themselves (4.2) and of the translation versions (5). The paper terminates with a brief comparison of professional and non-professional translation processes (section 6).
\end{abstract}

\section{MOTS-CLÉS/KEYWORDS}

translation problem, translation strategy, translation performance, translation version, translation process

\section{Introduction}

Up to the 1980s, translation theory was primarily concerned with two phenomena (Lörscher 1991a): with translation as a product and with translation competence.

Translation as a product that is a written text in a target-language (TL), which represents the result of a translation process, had been described and analysed by a comparison with the respective source-language (SL) text. The relation between the SL text and the TL text had been the object of the numerous and highly abstract models of equivalence (Koller 1978; ${ }^{2}$ 1983: 95; Ladmiral 1981: 393). In most cases, these models were prescriptive in nature and of very limited use for the practical translator.

Translation theory was mainly competence-oriented and concentrated on the internalized knowledge of the professional translator. The models of translation were theoretical and speculative rather than empirical, and were based on idealizations rather than on actually occurring data (Toury 1980: 41).

As a consequence of this orientation on product and competence, translation processes and translation performance remained largely unexplored (Reiß/Vermeer 
1984: 41; Krings 1986). This narrowing of the object and of the dimensions of investigation has only recently been recognized as a deficit. As a result, a new, processoriented, performance-analytical discipline has developed within translation studies (cf. Gerloff 1988; Jääskeläinen 1990; Krings 1986; Lörscher 1991a; Séguinot 1989; Tirkkonen-Condit 1991).

The considerations which will be made in this paper can be located within this area of research. They are based on a research project in which psycholinguistic aspects of the translation process are investigated by analyzing translation performance. This is done in order to reconstruct translation strategies. These underlie translation performance, operate in the translation process and thus are not accessible to direct inspection.

\section{The Design of the Investigation}

The empirical basis of the investigation was sixty orally performed and tape-recorded translations (German-English; English-German) of nine written texts. The oral form of translation was chosen, since presumably more aspects of the process of speech production - and thus also those of the translation process - can be externalized herein than would be the case in written translation.

During the first phase of the project, translation processes of advanced foreign language learners were investigated. The subjects - mostly students of English in lower semesters - had received no or only a minimal education in translation. They had only a partial competence in English beside their German mother tongue. The results brought forth are shown in my monograph Translation Performance, Translation Process, and Translation Strategies. A Psycholinguistic Investigation, Tübingen, 1991.

In 1992, the project entered its second phase in which the mental processes of professional translators were analysed. At the moment, a third phase is in preparation which will concentrate on bilinguals' translation processes (Lörscher [in preparation]).

\section{Methodology}

Concerning the methodology which has been applied for the investigation of the translation process, distinctions can be made between the methods for data collection and those for data evaluation.

\subsection{Methods of Data Collection}

As regards data collection, a combination of thinking-aloud and retrospective probing plays a decisive role as a method to discern the mental processes involved (Ericsson/Simon 1984). The subjects were asked to verbalize the thoughts that occurred to them as much as possible while they performed the translation task. In addition, the subjects were confronted with their translation problems shortly after their translation and were asked to comment on the problems and the ways in which they tried to solve them. During the last several years, many arguments have been put forward about the advantages and disadvantages of this procedure. Elsewhere (Lörscher 1991b), I pointed out seven arguments in favour of thinking-aloud as a method for the elicitation of data on translation processes. By way of conclusion, it 
can be assumed that thinking-aloud in combination with retrospective probing represents a useful instrument to formulate hypotheses on mental processes in general and about translation processes in particular. It goes without saying that both the situation in which the data has been externalized and its inherent limitations must be taken into account.

\subsection{Methods of Data Analysis and Evaluation}

The analysis and evaluation of data are carried out by means of an interpretive approach, as is customary in performance analysis. The primary aim of this approach is the hypothetical reconstruction of sense relations. In the process of interpretive reconstruction, certain data are interpreted as (observable) indicators of (unobservable, mental) translation strategies. These indicators represent the basis for the formation of hypotheses on the mental translation process. A more detailed description of these phenomena is discussed in Lörscher 1991a: 56-66.

The process of knowledge accumulation with respect to translation strategies has a dialectical nature. On the one hand, the analysts must have some knowledge of the concept of translation strategies in order to be able to ascribe the status of strategy indicators to their respective signs. On the other hand, translation strategies are only constituted by their indicators, so that knowledge of them can, to a very large extent, only be gained by means of strategy indicators. Therefore, the analysts must often proceed in a speculative and hypothetical way. They often do not interpret signs to be indicators because they know the respective entity, i.e. the strategy, but rather on the basis of considerations of probability. These can be corroborated or turn out to be false in the course of accumulating further knowledge of the phenomena and of acquiring more experience in interpretation (Lörscher 1991a: 56-66).

\section{A Strategic Analysis of the Process of Translation}

Translation strategies have been defined by me as procedures which the subjects employ in order to solve translation problems (Lörscher 1991a: 76-81). Accordingly, translation strategies have their starting-point in the realization of a problem by a subject, and their termination in a (possibly preliminary) solution to the problem or in the subject's realization of the insolubility of the problem at the given point in time.

Between the realization of a translation problem and the realization of its solution or insolubility, further verbal and/or mental activities can occur which can be interpreted as strategy steps or elements of translation strategies. They can be formalized to yield categories of a model for the strategic analysis of the translation process. A model of this type was developed on the basis of a corpus of translations made by foreign language students. In the second stage of the project, it was applied to translations performed by professional translators. Significant modifications of the model were unwarranted for an adequate analysis of professional translation processes although the quality and structure of the translation strategies and their elements, as well as their quantitative distribution differ considerably, at least in part (cf. section 6 for more details).

The model consists of two hierarchical levels. The first and lowest level contains those phenomena which can be interpreted to be elements of translation strategies, i.e. 
the smallest discrete problem-solving steps. The second level captures the manifestations of translation strategies. Translation versions can be located within strategies or can comprise several strategies, and are thus intra- or interstrategic phenomena. More about the hierarchical organization of the model will be pointed out in sections 4.3 and 5.

\subsection{Elements of Translation Strategies}

The elements of translation strategies can be distinguished as to whether they are original, i.e. constitutive, or potential. The former only occur within strategic, i.e. problem-oriented phases of the translation process and are thus original, constitutive elements of translation strategies. The latter may also occur within non-strategic phases of the translation process.

In my data corpus, 22 elements of translation strategies could be found. They are contained in Annex 1.

\subsection{Translation Strategies}

Translation strategies are procedures for solving translation problems. They range from the realization of a translational problem to its solution or the realization of its insolubility by a subject at a given moment. They are constituted by those minimal problem-solving steps outlined above.

The flow chart represented in Annex 2 shows the interplay of the elements of translation strategies and thus the decision paths available to the subjects when they are engaged in solving translational problems.

As the data show, the elements of translation strategies only combine in specific ways to build up structures. Accordingly, translation strategies contain one or more of these structures.

Following a model for the analysis of discourse, which I developed in a different context (Lörscher 1983), a distinction is made between basic structures, expanded structures, and complex structures of translation strategies. This is based on the fact that although translation strategies can be highly complex and thus difficult to document and describe in their manifold forms, they can be reduced to a fairly small number of relatively simple structures. The application of a generative principle allows the transformation of basic structures into expanded and complex structures.

The types of translation strategies used by the subjects of my investigations are schematically represented as follows.

Five types of basic structures occur in my data corpus:

Type I. : RP - (P)SP\#/SP

Type II. : RP - $\rightarrow$ SP - (P)SP\#/SP

Type III. : (RP) - VP - (P)SP\#/SP

Type IV. : $(\mathrm{RP})$ - $(\rightarrow \mathrm{SP})$ - VP - $(\rightarrow \mathrm{SP})$ - (P)SP\#/SP $\varnothing$; at least one $\rightarrow$ SP must be realized.

Type V. : (...) (P)SPa/SPaØ (...) (P)SPb/SPbØ (..) (P)SPc/SPc Ø (..)

Type I. is the easiest case to describe and consists of the recognition of a problem (RP), followed by the immediate solution of the problem or the recognition of the momentary insolubility of the problem. According to the generative principle, types 
II. to IV. can be derived from type I. Type II. contains an additional phase of searching for a solution (SP), type III. contains an additional verbalization of the translational problem (VP), and type IV. contains both an additional phase of searching $(\rightarrow \mathrm{SP})$ and a verbalization (VP). Type V. is the splitting-up structure. When a complex translation problem cannot be solved as a whole at a time, subjects often split it up into several parts $(\mathrm{a}, \mathrm{b}, \mathrm{c})$ and try to solve these successively.

Expanded structures of translation strategies consist of a basic structure which contains one or more expansions. Expansions are defined as additional elements of a strategy itself. For example, the strategy RP - VP - $\rightarrow$ SP - VP2 - $\rightarrow$ SP - PSP contains a type IV. structure, i.e. RP - $(\rightarrow \mathrm{SP})$ - VP - $(\rightarrow \mathrm{SP})$ - (P)SP, with two additional elements of the structure itself, (VP2, $\rightarrow \mathrm{SP})$, i.e. with two expansions.

Complex Structures are built up of several basic and/or expanded structures. An example serves to elucidate this procedure. The strategy VP - SP $\varnothing \rightarrow$ SP - PSP contains a type III. and a type II. structure. The former is terminated by SPØ, i.e. with the subject setting the problem aside in order to try solving it later. The second part of the strategy is the realization of a type II. structure. It terminates with a preliminary solution to the translation problem.

\subsection{Translation Versions}

As shown in the previous sections, the translation process contains both strategic phases, which are directed towards solving translational problems, and non-strategic phases, which aim at accomplishing tasks. The former phases range from the realization of a translational problem to its solution or to the realization of its insolubility at a given point in time. The latter phases start with the extraction of a unit of translation and terminate when it has been (preliminarily) rendered into TL or when a translational problem arises. Whereas translation strategies can, by definition, only occur within strategic phases of the translation process, translation versions can be localized within strategic or non-strategic phases, or can extend from strategic into non-strategic phases or vice versa.

As my data reveal, the subjects often produce several translation versions. They can comprise the entire text or only parts of it (e.g. paragraphs, sentences, clauses, or phrases). The production of several translation versions can have various reasons, of which at least four can be interpreted from the data:

i. If subjects do not succeed in solving a translational problem on the first attempt, they may try to solve the problem in its wider context. This may require more than two translation versions which may also contain non-strategic parts of the translation.

ii. If, on the first attempt, subjects do not succeed in rendering a strategic or non-strategic part of an SL text into TL in a way which is considered adequate, they may try to optimize the TL text production by conceiving a more adequate translation in another version.

iii. If subjects, while checking a complex TL text segment, find an alternative, they may conceive a further translation version which contains the alternative TL text segment plus part of its context.

iv. If subjects translate a complex SL text segment consisting of several strategic and/or non-strategic parts by successively rendering its components into TL, subjects may produce a further version of the TL text segment. Thus, they may sense the complex interrelationships between the components of the TL text segment. They may realize that 
the components, in order to make an adequate stretch of TL discourse, cannot be put together in the same way as they were successively translated from the SL.

As far as the investigation of translation strategies is concerned, the potential conception of several translation versions by subjects plays an important part because translation strategies and translation versions are interconnected in various ways.

Two cases are of special interest here:

In the first case, a further translation version contains one or more translation strategies. They are called intraversional strategies.

In the second case, a translation strategy contains one or more translation versions. They are called intrastrategic versions.

\section{Example of an intraversional translation strategy /S28/}

\begin{tabular}{ll|}
$\begin{array}{ll}\text { Text } \\
\text { vielleicht fang ich nochmal ganz }\end{array}$ & Category of Analysis \\
$\begin{array}{l}\text { anders an } \\
\text { (1s) ehm (4s) }\end{array}$ & $\rightarrow$ TRANS \\
vielleicht fangen wir mal so an \\
mit dem 'on which the decision' & OTL \\
(1s) ehm (2s) & $<$ MSL> \\
Für die Entscheidung & RP/ $\rightarrow$ SP \\
(9s) & SP \\
der Versammlung & OSL/OTL \\
(3s) & MTL \\
der Universität Oxford & OSL \\
(3s) & T \\
Mrs Thatcher (1s) & OSL \\
das vorgeschlagene & Ti. \\
(5s) & Tii. \\
Nee & CHECK \\
den vorgeschlagenen (1s) & Tii.- \\
Ehrengrad zu verweigern & REPHR.TL(Tii.) \\
gibt es kein wie auch immer & T \\
geartetes mögliches Argument. & MTL T4\#
\end{tabular}

The example presented contains the fourth translation version of a complex text segment which consists of several clauses and phrases and can only be rendered into TL by a transposition of its parts. Within the fourth translation version, a strategy is to be found. The subject realizes a translational problem, i.e. the transfer of the SL text segment 'on which the decision' into TL. After a phase of searching, the subject arrives at a solution and verbalizes it. The translation strategy thus consists of a type II structure. 


\section{Example of an Intrastrategic Translation Version /S24/}

Text

ach, 'mit wem' hab ich doch

vergessen (4s)

they have to know (1s)

when

(7s)

to use (2s)

to whom, no, ah

(3s)

'wann welches Deutsch mit wem

gesprochen wird'

(2s)

they have to know

(1s) when

(2s) they have (1s) to use

(10s)

oder (1s)

when

(2s) ehm (4s)

to

when to talk

(1s) with whom (1s) in which (1s)

kind of German.
Category of Analysis

$\rightarrow \mathrm{T} 3$

MTL

MTL

$\mathrm{RP} / \rightarrow \mathrm{SP}$

$\mathrm{SPa}=\mathrm{MTL}$

$\mathrm{SPb}=\varnothing \mathrm{T} 3 \#$

$\rightarrow$ SP

VP

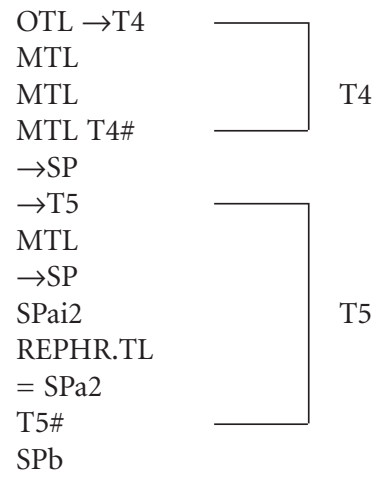

The transcribed segment of translation contains a strategy which ranges from the realization of a translational problem to the solution of its last part $(\mathrm{SPb})$. The strategy is complex in nature. It contains a type $\mathrm{V}$ splitting-up basic structure, with a solution consisting of two parts ( $\mathrm{SPa}$ and $\mathrm{SPb}$ ), expanded by a phase of searching $(\rightarrow \mathrm{SP})$, two embedded elements $(\mathrm{SPb}=\varnothing, \mathrm{VP})$, as well as two (intrastrategic) translation versions of a previously verbalized problematic SL text segment (VP). Version 4 (i.e. T4) consists of three phases of monitoring of TL text segments (MTL). Version 5 (i.e. T5) comprises a phase of monitoring of a TL text segment (MTL) and a type $\mathrm{V}$. basic structure strategy which is thus an intraversional type V. translation strategy.

\section{On the Hierarchical Organization of the Translation Process}

The discussion of the two examples of intraversional strategies and intrastrategic versions has revealed an aspect of the translation process which is probably of eminent importance for a comprehensive investigation comprising the strategic and non-strategic dimension of the translation process: the hierarchical organization of the translation process. It manifests itself in structural and functional ways.

1. Structural hierarchy means the fact that certain elements and structures bear a relationship of super- and subordination. The model presented is organized on two hierarchical levels. It analyses translation performance on the level of the elements of translation strategies and on the superordinate level of the translation strategies themselves. The structures of the superordinate level (i.e. translation strategies) consist of at least two elements of the subordinate level. Rank shift, i.e. the fact that one element of a hierarchically lower level can, at the same time, function as a unit on a hierarchically higher level, is thus not possible. 
2. Functional hierarchy means that the model can capture superordinate goals. The hierarchical organization of goals in translation becomes most obvious in translation versions. These are derived from a maxim which dominates an entire translation and according to which a translation should not merely convey the sense and/or function of the SL text into TL, but should be an adequate piece of discourse produced according to the TL norms of language use.

In example I, the subject's endeavour to conceive a new translation version (T4) is superordinate to the entire part of discourse which follows. All utterances between $\rightarrow \mathrm{T} 4$ and T4\# are produced under the subject's superordinate aim. This also applies to the intraversional strategy. The subject's endeavour to conceive a further translation version can be considered to be a realization of her global aim which is superordinate to the entire translation, i.e. to produce a TL text which is as adequate as possible and which not only conveys the sense of the SL text, but which also corresponds to the TL norms of language use and its conventions of text production. This aim, which has the character of a maxim, is, however, not pursued by all the subjects. Lack of knowledge and/or inability may be the reason(s) for this.

Example II reveals an even more complex structure of relations of super- and subordination. The transcribed segment of a translation starts with a subject conceiving a third translation version for an SL text segment. Within this version, a translation strategy is initiated by a problem which the subject is faced with when she conceives the version. The strategy continues after the version has been completed. It thus has a partly intraversional character and is dominated by the superordinate aim of the version (T3). The translation strategy itself is superordinate to the versions 4 and 5 . They are dominated by the subject's aim of solving the translation problem which she has realized and verbalized.

\section{Professional and Non-Professional Translation Processes: A Brief Comparison}

The findings which have been discussed in the previous sections are relatively independent as to whether the subjects are professional or non-professional translators. In this concluding section, some aspects of translation processes of professionals are compared with those of advanced foreign language learners.

The differences between the two groups of translators have been identified on the basis of my data. Since the investigation is still in progress, the following considerations are of a preliminary kind.

The first point I would like to make is that in spite of the differences, professional and non-professional translation processes have many features in common. The fact that the categories of my model of analysis, which were developed on the basis of non-professional translations, adequately capture professional translations, as well, clearly suggests that the two kinds of mental processes are similar. From the point of view of the strategies detected, the mental processes of the two kinds of translators did not reveal significant differences.

As a quantitative analysis of the translation strategies shows, differences between professional translators and foreign language students can be detected in the distribution and frequency in the types of strategy, i.e. in the quantitative aspects of the 
translation strategies. Furthermore, the process-oriented approaches to the translations taken by professional and non-professional translators differ quite considerably.

1. Most of the foreign language students take a form-oriented approach in that they produce translations mainly by an exchange of language signs. In the data elicited by me and by other scholars, numerous examples of inadequacies and deficits resulting from such a form-oriented approach can be found. Since the foreign language students generally approach their translations in a form-oriented way, the monitor which checks on the sense of their translations remains largely inactive. As a result, TL texts are produced which are neither equivalent in sense to the respective SL texts nor grammatically or stylistically acceptable texts by themselves. This is even true of texts in the subjects' mother tongue. They, too, often reveal the deficits just mentioned. Obviously, this is not caused by lack of competence. When the subjects were confronted with their own translations some time after the translation task, they could hardly believe that they had produced texts in their native language with such a high degree of grammatical and stylistic errors. The subjects would certainly not have made these errors if their task had only been to produce a text with a certain meaning in their mother tongue. The deficits in the TL texts are mainly caused by the task of translating and the subjects' form-oriented approach to translation which prevents any checking on the sense of the TL text produced. Professional translators, in contrast, commonly employ sense-oriented procedures (cf. Lörscher 1997). Thus, the shortcomings of translations with serious distortions of sense or violations of norms of TL text production are avoided.

2. The units of translation, i.e. the SL text segments which subjects extract and put into their focus of attention in order to render them into the TL as a whole, are considerably larger among professional translators than among foreign language students. In other words, the processing system of professionals can obviously address larger units than that of non-professionals. The former mainly choose phrases, clauses or sentences as units of translation whereas the latter concentrate on syntagmas and especially on single words. As a consequence, professional translators often realize problems while they are rendering a unit of translation into the TL. The foreign language students, however, usually realize translation problems before they start translating because the units they extract from the SL text are much smaller. Consequently, problems can be located more easily and more quickly. Furthermore, it is mainly problems of a local kind, especially lexical transfer problems arising from lack of competence in SL or TL, which the non-professionals are faced with whereas the professionals are primarily concerned with global, formulating problems, with the optimal expression of sense according to the TL norms of text production.

3. As pointed out elsewhere (Lörscher 1991c), foreign language students tend not to check those TL utterances according to their sense which they have translated and within which they did not realize any problems. As a consequence, the translations of the students more often than not reveal utterances which contain grammatical errors, even in their mother tongue, violations of TL text production norms, or which make no sense. Professional translators, however, tend to continuously check their TL text output, no matter whether it has been produced with or without any problems involved. As a result, professional translators often do not realize formulating problems before they check their utterances produced in TL. This ex-post realization 
of translation problems is an important distinguishing factor of professional and non-professional translation processes.

4. The professional translators mainly, although not exclusively, check their utterances produced in TL with regard to their stylistic and text-type adequacy. The foreign language students, by contrast, only check the solutions to their problems, and this checking is done with respect to lexical equivalence and, to a lesser extent, to their syntactic correctness. Stylistic and text-type adequacy plays a subordinate role, if any, for them. Thus their translation processes are dominated, if not determined by the lexis and syntax of the SL text. As a result, texts in the TL are produced which are often deficient and unacceptable because they contain violations of TL norms of text production. Such deficiencies can, at least in principle, be avoided by the different checking procedures generally employed by the professional translators.

I owe great thanks to Peter Tosic, who, as a native speaker of English, critically looked through the English version of the manuscript.

\section{REFERENCES}

Ericsson, K.A. H. A. Simon (1984): Protocol Analysis. Verbal Reports as Data, Cambridge/Mass., MIT Press.

Gerloff, P.A. (1988): From French to English: A Look at the Translation Process in Students, Bilinguals, and Professional Translators, Mimeo, Harvard University.

JäÄskeläinen, R.H. (1990): Features of Successful Translation Processes: A Think-Aloud Study, Mimeo, University of Joensuu, Savonlinna School of Translation Studies.

Koller, W. (1978): Äquivalenz in kontrastiver Linguistik und Übersetzungs-wissenschaft, in L. GräHs et al. (eds.): Theory and Practice of Translation, Nobel Symposium 39, Stockholm, September 6-19, 1976. Bern, P. Lang, p. 69-92.

Koller, W. (1983): Einführung in die Übersetzungswissenschaf, Heidelberg, Quelle und Meyer.

KrINGs, H.P. (1986): Was in den Köpfen von Übersetzern vorgeht, Eine empirische Untersuchung der Struktur des Übersetzungsprozesses an fortgeschrittenen Französischlernern, Tübingen, G. Narr.

LADMiRal, J.R. (1981): La traduction comme linguistique d'intervention in W. PöckL (ed.): Europäische Mehrsprachigkeit. Festschrift zum 70, Geburtstag von Mario Wandruszka, Tübingen: G. Narr, p. 375-400.

LÖRsCher, W. (1983): Linguistische Beschreibung und Analyse von Fremdsprachenunterricht als Diskurs, Tübingen, G. Narr.

LÖrscher, W. (1991a): Translation Performance, Translation Process, and Translation Strategies. A Psycholinguistic Investigation, Tübingen: G. Narr.

Lörscher, W. (1991b): “Thinking-Aloud as a Method for Collecting Data on Translation Processes," in Tirkkonen-Condit, S. (ed.) 1991, p. 67-77.

Lörscher, W. (1991c): “Investigating the Translation Process," Interface 6.1, p. 3-22.

Lörscher, W. (in preparation): Translation as Process, An Empirical Investigation into the Translation Processes of Professionals, Bilinguals, and Foreign Language Learners.

Reiss, K. / H.J. Vermeer, (1984): Grundlegung einer allgemeinen Translationstheorie, Tübingen, M. Niemeyer.

SÉguinot, C. (ed.) (1989): The Translation Process. Toronto: York University Press.

TirkKonen-Condit, S. (ed.) (1991): Empirical Research in Translation and Intercultural Studies, Selected Papers of the TRANSIF Seminar, Savonlinna 1988, Tübingen, G. Narr.

Toury, G. (1980): In Search of a Theory of Translation, Tel Aviv. 


\section{ANNEX 1}

Twenty-two elements of translation strategies:

Original Elements of Translation Strategies

$\begin{array}{lll}\text { RP } & : & \text { Realizing a Translational Problem } \\ \text { VP } & : & \text { Verbalizing a Translational Problem } \\ \rightarrow \text { SP } & : & \text { Search for a (possibly preliminary) Solution to a Tanslational Problem } \\ \text { SP } & : & \text { Solution to a Translational Problem } \\ \text { PSP } & : & \text { Preliminary Solution to a Translational Problem } \\ \text { SPa,b,c.. } & : & \text { Parts of a Solution to a Translational Problem } \\ \text { SP } \varnothing & : & \text { A Solution to a Translational Problem is still to be found }(\varnothing) \\ \text { SP }=\varnothing & : & \text { Negative }(\varnothing) \text { Solution to a Translational Problem } \\ \text { PSL } & : & \text { Problem in the Reception of the } S L \text { Text }\end{array}$

Potential Elements of Translation Strategies

MSL : $\quad$ Monitoring (verbatim repetition) of SL Text Segments

MTL : $\quad$ Monitoring (verbatim repetition) of TL Text Segments

REPHR.SL : $\quad$ Rephrasing (paraphrasing) of SL Text Segments

REPHR.TL : Rephrasing (paraphrasing) of TL Text Segments

CHECK : Discernible Testing (= Checking) of a (preliminary) Solution to a Translational Problem

OSL $\quad: \quad$ Mental Organization of $S L$ Text Segments

OTL : : Mental Organization of TL Text Segments

REC : Reception (first reading) of SL Text Segments

$[\mathrm{TS}]_{\text {com }} \quad: \quad$ Comment on a Text Segment

TRANS : Transposition of lexemes or combinations of lexemes

T : $\quad$ Translation of Text Segments without any problems involved

$\rightarrow \mathrm{T} 2,3, . . \mathrm{n} \quad$ : $\quad$ Conceiving a Second, Third, etc. Translation Version

ORG : Organization of Translational Discourse

ANNEX 2

Flow Chart of Translational Problem Solving

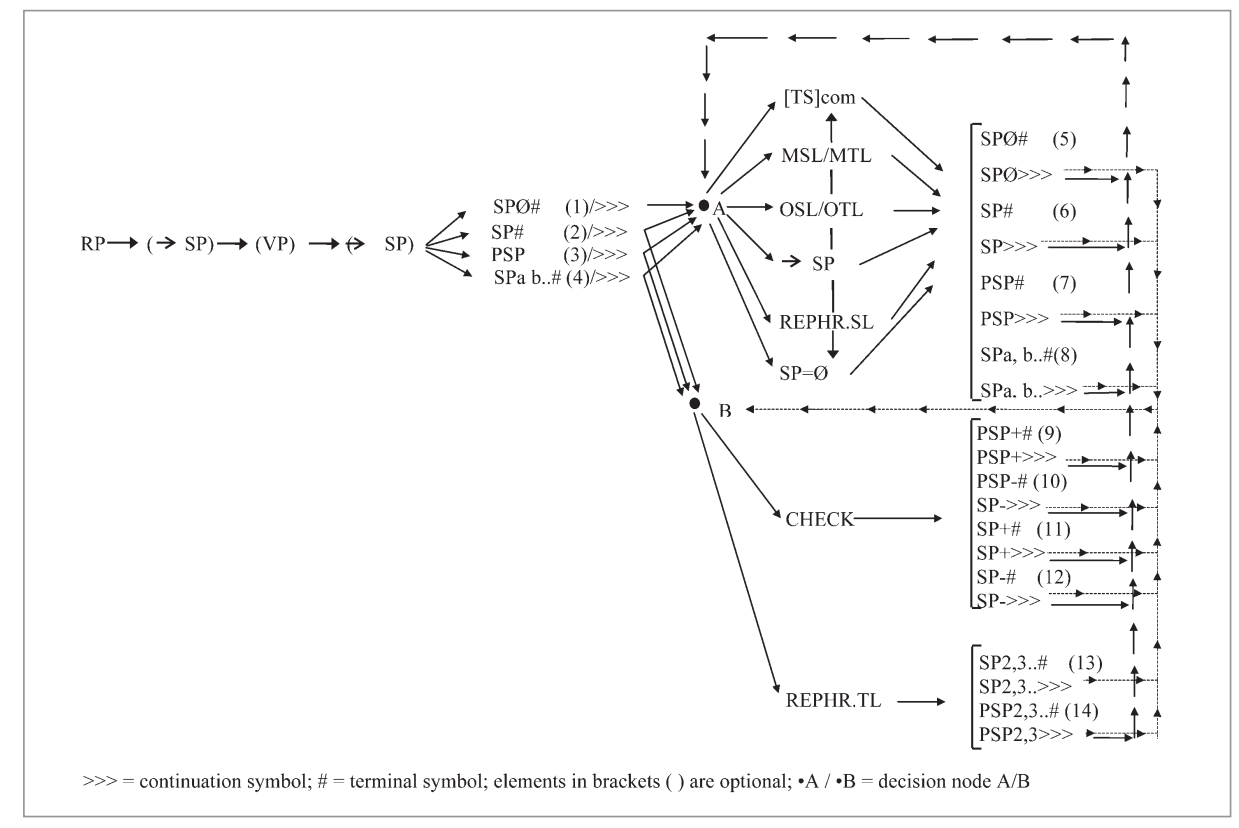




\section{Explanatory Remarks to the Flow Chart of Translational Problem-Solving}

After realizing (RP) and possibly verbalizing (VP) a translational problem, and after a potential search for a solution $(->$ SP), subjects may achieve a solution (SP, SPa,b...) or a preliminary solution (PSP) immediately (2), (3), (4), in which cases the problem-solving process may come to an end (\#). This may also be the case when subjects consider a problem insoluble (1). Having found a (preliminary) solution (2), (3), (4), subjects may go on dealing with the problem ( $>>>$ ) and proceed to either decision node A or B $(\bullet A ; \bullet B)$. Decision nodes are "points" at which several problemsolving means are available to the subjects. When subjects cannot find a solution (SPØ), they can only proceed to decision node A. Having reached decision node A, subjects may try to bring about a solution by monitoring SL or TL text segments (MSL, MTL), and/or by rephrasing SL text segments (REPHR.SL), and/or by (further) searching for a solution (->SP), and/or by mentally organizing SL or TL text segments (OSL, OTL), and/or by commenting on text segments ([TS $]_{\text {com }}$ ), and/or by conceiving a negative solution $(S P=\varnothing)$. As a result of these problem-solving activities, subjects may either find a (preliminary) solution to the problem (PSP, SP, SPa,b...) or not (SPØ). Here again, the problem-solving process may come to a successful (6), (7), (8) or to an unsuccessful (5) end.

When subjects decide to continue, they may either go back to decision node $\mathrm{A}$, which is possible after SPØ, PSP, SP, and SPa,b...; or they may proceed to decision node $\mathrm{B}$, which, however, is not possible after SPØ.

Having reached decision node $\mathrm{B}$, subjects continue by rephrasing (REPHR.TL) the respective TL text segment (SP, PSP, SPa,b...) or by testing it (CHECK). The result of the rephrasing is a new

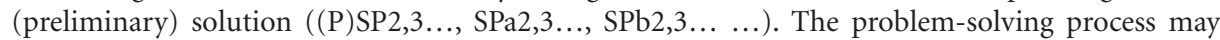
come to an end here again, as in (13) and (14), or subjects may proceed to one of the decision nodes again.

After the testing of a TL text segment, the (preliminary) solution may either be corroborated $((\mathrm{P}) \mathrm{SP}+)$ or rejected $((\mathrm{P}) \mathrm{SP}-)$. In both of these cases, subjects may terminate the problem-solving process (9), (10), (11), (12) or proceed to either decision node A or B. 